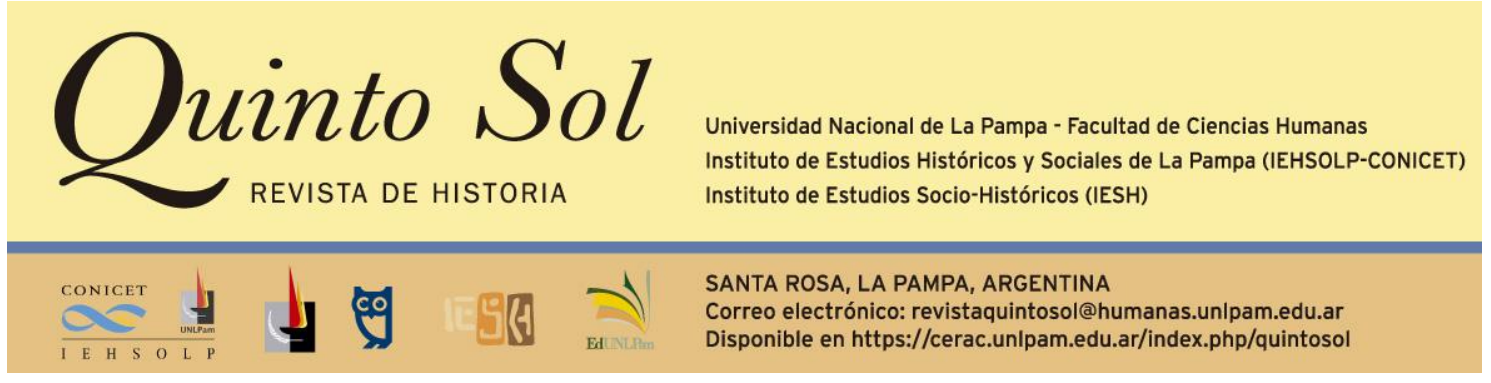

Quinto Sol, vol. 25, n 1, enero-abril, ISSN 1851-2879, pp. 1-4

https://doi.org/10.19137/qs.v25i1.5522

Esta obra se publica bajo licencia Creative Commons 4.0 Internacional. (Atribución-No ComercialCompartir Igual)

\title{
Claudia Salomón Tarquini, Sandra R. Fernández, María de los Ángeles Lanzillotta y Paula I. Laguarda (Eds.) EI hilo de Ariadna. Propuestas metodológicas para la investigación histórica. Prometeo, 2019, 340 páginas.
}

\section{Andrés G. Freijomil}

Universidad Nacional de General Sarmiento. Instituto de Ciencias. Director del área de investigación Poéticas de la historiografía

Argentina

Correo electrónico: freixomil@gmail.com

En el marco de una conversación entre Pierre Bourdieu y Lutz Raphael propuesta por la revista Geschichte und Gesellschaft en octubre de 1989, el sociólogo francés lamentaba que los historiadores (sobre todo, los de la tradición annaliste) se esforzasen por escamotear los secretos de fabricación propios del oficio e hiciesen de su práctica tanto en lo referido al uso de conceptos como al de sus técnicas y metodologías- una suerte de cifrado aristocrático. Con tal arcano, según Bourdieu, los historiadores no hacían más que disimular la distinción de sus métodos puesto que cualquier aprendizaje del oficio, lejos de toda posible democratización, sólo se podía adquirir con el tiempo. A esta misma situación de vacío aluden las editoras de El hilo de Ariadna cuando recuerdan con pesar la típica expresión "a investigar se aprende investigando" y para cuyo extremo empirismo el único consejo que suele ofrecerse a la hora de poner manos a la obra más bien parece un penoso subterfugio: "lo usual en estos casos". 
A diferencia de lo que ocurre con el resto de las ciencias sociales donde la profusión de manuales metodológicos nunca ha cesado, los de metodología histórica otrora esenciales para consolidar la cientificidad de la disciplina entre fines del siglo XIX y la primera mitad del $X X$, aunque con piezas normativas demasiado obsesionadas con la búsqueda policial del error como las de Bernheim o de Langlois y Seignobos- fueron cayendo en un paulatino descrédito hasta desaparecer casi por completo del horizonte de producción de los historiadores. Si bien los niveles de especialización han imposibilitado todo conato por unificar criterios comunes entre áreas de investigación histórica cada vez más atomizadas -algo de lo que da cuenta la obra que reseñamos-, lo cierto es que cualquier remedo metodológico pasó a ser visto en historia como un pecado determinista, como una invasión de las huestes especulativas sobre la experiencia de los agentes o, en suma, como un facilismo pedagógico que sólo buscaba uniformizar la densidad de una noble y compleja tarea. Tan sólo persistieron como de soslayo algunos manuales -en el ámbito hispanoparlante, el tratado de Julio Aróstegui, citado con frecuencia en El hilo de Ariadna, es uno de ellos- mientras otros sobrevivieron a riesgo de permanecer anclados en campos muy específicos, pero siempre utilizados de forma recóndita como sospechosos insumos universitarios. Así pues, salvo por aquel período "metódico" (durante el cual sólo se avanzó sobre las técnicas, pero no sobre la teoría) y tras las posiciones antihegelianas (más aparentes que reales) de Ranke, tras las invectivas de Lucien Febvre contra la filosofía (en realidad, de la historia) o, inclusive, tras las querellas del marxismo británico de corte thompsoniano con su alegato de lo empírico y el work in progress como única opción para devenir historiador profesional, se fue configurando en nuestra disciplina un sentido común según el cual era posible y hasta deseable prescindir tanto de la formalización metodológica explícita (que sólo comienza cuando el aspirante a historiador emprende su tesis) como de la reflexividad teórica (que, por lo general, nunca se realiza) puesto que ambas, cual bestia bicéfala, parecían sólo dirigidas a prescribir la libertad de toda investigación. Sin embargo, se trata de dos tipos de adiestramiento que la historia necesita, desde luego, como cualquier otro saber científico y que los historiadores dejaron, sobre todo en lo que atañe a la esfera teórica, en manos de la filosofía. Con todo, tras la convulsión epistemológica que sufrió el conocimiento científico del mundo social en los años 1970 y, en especial, tras la conmoción operada por el giro lingüístico, esta situación ha ido cambiando paulatinamente mediante algunas tradiciones que han atemperado ese rechazo. Tal es lo que ha ocurrido, por ejemplo, con el aliento teórico de buena parte de la producción koselleckiana, con esa suerte de gran teoría literaria de la historia postulada por Hayden White, con las premisas metodológicas de la microhistoria italiana, insertas como parte de su trama narrativa, con los entresijos de una sociología de los historiadores en Michel de Certeau, o con los fecundos análisis teóricos de François Hartog para pensar la temporalidad histórica. Y tal es, precisamente, el contexto donde aparece El hilo de Ariadna, cuyo primer desafío no es sino romper aquel estigma de lo preclaro y ofrecer, no un manual celebratorio del método ni tampoco una secuencia normativa de procedimientos inevitables, sino más bien un nutrido cuaderno de bitácora organizado alrededor de las tres grandes herramientas que necesita todo 
historiador: una serie de recursos epistemológicos transversales, la consideración de las cuestiones técnicas y un acervo de posibilidades heurísticas.

Con una pluralidad de intereses cuya factura tripartita recuerda la disposición de las clases que Johann G. Droysen dictara sobre la "enciclopedia" y metodología de la historia entre 1857 y 1864 (más tarde, publicadas bajo el título de Histórica), El hilo de Ariadna recupera así un tipo de producción que, tras aquella obra de Droysen y como consecuencia de la inopia teórica de la influyente "escuela metódica" (y siempre mal llamada positivista), ya no tuvo verdadera continuidad: una serie coral de múltiples propuestas y experiencias de investigación histórica, pasibles de ser transmitidas a la comunidad científica que, a su vez, funcionen como puntos de partida para futuras indagaciones sobre el pasado histórico. En tal sentido, los historiadores encontrarán en esta obra colectiva una inestimable gama de aparejos que les permitirá precisar nomenclaturas, ejercitarse en la observación documental, refinar los métodos de análisis, orientarse en las posibilidades hermenéuticas e incorporar nuevos objetos al esbozo general que aquí sugieren las cuatro historiadoras que editan la obra y quienes, vale recordarlo, llevan muchos años trabajando y reivindicando este tipo de transmisión, así como diversas y novedosas tipologías de saberes históricos en el ámbito universitario.

El hilo de Ariadna está compuesto por treinta y dos capítulos breves en el marco de un tríptico cuyos tres ejes presentan límites más bien porosos con el visible fin de darle operatividad a la cartografía general de la obra. El primer eje comienza con un capítulo -el único de carácter teórico- que aborda una serie de cuestiones epistemológicas en clave filosófica y recupera una serie de figuras clásicas como Comte, Marx o Popper para culminar con el impacto que tuvieron en la historiografía. Luego, a partir de los siguientes capítulos, se analizan el problema de las escalas y la distribución de la espacialidad, la relación entre la investigación y la enseñanza de la historia y, finalmente, se ofrece una caja de herramientas para relevar archivos digitales. El segundo eje acomete la tarea de revisar las técnicas cualitativas y cuantitativas al uso del historiador $y$, de este modo, acercar la historia a todo lo que tiene o comparte con las ciencias sociales. Así pues, se examinan la intervención cliométrica, los usos del análisis y la observación documental, la importancia de las biografías individuales y colectivas, el análisis crítico de las fuentes orales, el uso de las imágenes y del cine, el rol de los discursos sociales, la potencialidad que encierran las redes sociales y un examen de los elementos georreferenciales y territoriales para pensar el pasado. Finalmente, el tercer eje -el más extenso y supeditado a la diversidad de fuentes primarias y archivos como puntos de partida- campea por una serie de objetos históricos tales como la economía, el mundo agrario y rural, la demografía histórica, la salud y las enfermedades, las historias de género, el movimiento obrero, una historia reciente de los trabajadores, la historia indígena, la historia religiosa, la historia de la guerra, la historia judicial, la historia de los gobiernos nacionales y provinciales, las burocracias de los territorios nacionales, los partidos políticos, la historia social de la educación, la historia intelectual, los usos de la prensa y de la música. Frente a tal diversificación, cabe preguntarse si estamos frente a un manual de metodología de investigación "histórica" (si atendemos al subtítulo de la obra) o "historiográfica" (si 
seguimos la forma de darle título a la Presentación). En todo caso, esta equiparación conceptual -deliberada o no- da cuenta de un claro estado de situación en la comunidad histórica: ya no es posible separar netamente el pasado reconstruido por el historiador respecto de las formas en que lo enuncia, representa y difunde por escrito. $Y$ es allí, en el armazón de los diferentes pliegos interdisciplinares de este polifacético cuaderno de bitácora, donde El hilo de Ariadna reconoce plenamente su identidad como escritura de la historia.

De este modo, la obra no sólo funciona como una valiosa guía de perplejos, sino también como un balance de los más recientes métodos de producción historiográfica utilizados por una zona de los historiadores argentinos durante los últimos veinte años. A tal efecto, el trabajo en su conjunto funge como un primer faro para rastrear aquellos objetos que fueron mayormente atendidos, pero también para detectar cuáles son aquellos que aún aguardan su especialista. Naturalmente, existen objetos históricos que no han sido abordados y que cuentan en Argentina con un desarrollo muy consolidado o bien en ciernes, pero, tal como se expresa en la Presentación, la obra, desde luego, no puede abarcarlo todo. En realidad, los principios de la selección temática y el sustrato de la estructura organizativa elegidas por las editoras obedecen a otra de las singularidades que depara la obra: su carácter notoriamente situado. Si bien El hilo de Ariadna fue publicado en la ciudad de Buenos Aires, casi todos los colaboradores proceden de universidades y centros de investigación arraigados en distintos puntos del país (Rosario, Santa Rosa, Mar del Plata, Tandil, La Plata, Capital Federal, Tucumán, Neuquén o Trelew). De allí que nada tenga de fortuito que la autoría del prólogo pertenezca a la gran especialista en historia regional, Susana Bandieri, una elección que funciona casi como una sutil manifestación de principios en un intento, en primer lugar, por visibilizar una producción científica diseminada en numerosas instituciones académicas provinciales no siempre reconocidas $y$, en segundo lugar, por federalizar los resultados de una práctica histórica que, si realmente creemos en las virtudes de una historia global, no pueden continuar sumidos bajo la ya insostenible dicotomía centro-periferia. A este respecto, El hilo de Ariadna hace mucho por expandir el tono de una serie de investigaciones que, por cierto, ya cuentan con una extensa y fértil tradición en aquellas instituciones de origen y que, pese a las posibilidades de mayor circulación ofrecidas por las nuevas tecnologías, aún precisa de mayores niveles de inserción en la comunidad científica de nuestro país. Es decir, no estamos ante producciones meramente "locales", sino ante piezas necesarias para comprender una trama histórica nacional que debería ser entendida no sólo de un modo interprovincial sino, sobre todo, transprovincial. En este sentido, el título elegido para la obra no podría haber sido más elocuente y promisorio. 